\title{
Advances in labor analgesia
}

This article was published in the following Dove Press journal:

International Journal of Women's Health

5 October 2009

Number of times this article has been viewed

\section{Cynthia A Wong}

Department of Anesthesiology, Northwestern University Feinberg School of Medicine, Chicago, IL, USA
Correspondence: Cynthia A Wong Department of Anesthesiology, Northwestern University Feinberg School of Medicine, 25I E. Huron St., F5-704, Chicago, IL 606 I I, USA Tel + I 3I2 4723585

Fax + I 3124723590

Email c-wong2@northwestern.edu
Abstract: The pain of childbirth is arguably the most severe pain most women will endure in their lifetimes. The pain of the early first stage of labor arises from dilation of the lower uterine segment and cervix. Pain from the late first stage and second stage of labor arises from descent of the fetus in the birth canal, resulting in distension and tearing of tissues in the vagina and perineum. An array of regional nerve blocks, systemic analgesic, and nonpharmacologic techniques are currently used for labor analgesia. Nonpharmacologic methods are commonly used, but the effectiveness of these techniques generally lacks rigorous scientific study. Continuous labor support has been shown to decrease the use of pharmacologic analgesia and shorten labor. Intradermal water injections decrease back labor pain. Neuraxial labor analgesia (most commonly epidural or combined spinal-epidural) is the most effective method of pain relief during childbirth, and the only method that provides complete analgesia without maternal or fetal sedation. Current techniques commonly combine a low dose of local anesthetic (bupivacaine or ropivacaine) with a lipid soluble opioid (fentanyl or sufentanil). Neuraxial analgesia does not increase the rate of cesarean delivery compared to systemic opioid analgesia; however, dense neuraxial analgesia may increase the risk of instrumental vaginal delivery.

Keywords: labor analgesia, neuraxial analgesia, epidural analgesia, childbirth pain

The pain of childbirth is arguably the most severe pain most women will endure in their lifetimes. The modern era of childbirth analgesia began in 1847 when Dr James Young Simpson administered ether to a woman in childbirth, and later in the same year, chloroform. Several years later John Snow successfully administered chloroform to Queen Victoria during the birth of her eighth child. Dämmerschlaf, or "twilight sleep," a combination of systemic morphine and scopolamine, was first described in the early twentieth century. ${ }^{1}$ Regional anesthesia was introduced in 1884 when Carl Koller described the use of cocaine to anesthetize the eye. Descriptions of spinal, lumbar and caudal epidural, paravertebral, and pudendal nerve blocks for obstetrics were published between 1900 and $1930 .{ }^{2}$ Continuous neuraxial analgesia, as it is practiced today, had its birth in the mid-twentieth century when Hingson and Edwards published the first report of continuous caudal analgesia for childbirth in $1943 .^{3}$

An array of regional nerve blocks, systemic analgesic, and nonpharmacologic techniques are currently used for labor analgesia. This review will summarize the 
physiology of childbirth pain, labor analgesic techniques, and the effects of labor analgesia on the mother and infant.

\section{Pathophysiology of childbirth pain}

Although the amount of pain and suffering associated with labor and vaginal delivery varies widely among parturients, few well-designed studies on the prevalence, intensity, and quality of labor pain have been performed. Melzack and colleagues used the McGill Pain Questionnaire to measure pain during labor and delivery (Figure 1). ${ }^{4}$ Nulliparous women had a higher total mean pain rating index (PRI) than parous women. Significant differences were also found between nulliparous and parous women in the sensory qualities of pain. Although scores ranged from mild to excruciating, the PRI scores of laboring women were 8 to 10 points higher than those associated with cancer pain, phantom limb pain, and postherpetic neuralgia.

Pain during the first stage of labor (start of labor until complete cervical dilation) originates predominantly in the cervix and the lower uterine segment, rather than the body of the uterus. ${ }^{5,6}$ Dilation of the cervix and lower uterine segment results in tissue distension, stretching, and tearing. During the late first stage and second stage of labor (complete cervical dilation until delivery) the fetus descends in the birth canal and the progressively greater pressure of the fetus on the vagina and perineum become additional sources of pain. Distension of the birth canal causes intense stretching and

$\begin{array}{ccc}\begin{array}{c}\text { Chronic pain syndromes } \\ \text { and }\end{array} & \begin{array}{c}\text { McGill questionnaire } \\ \text { pain scores }\end{array} & \begin{array}{c}\text { Pain after } \\ \text { labor pain }\end{array} \\ \text { (PRI) } & \text { accidents }\end{array}$

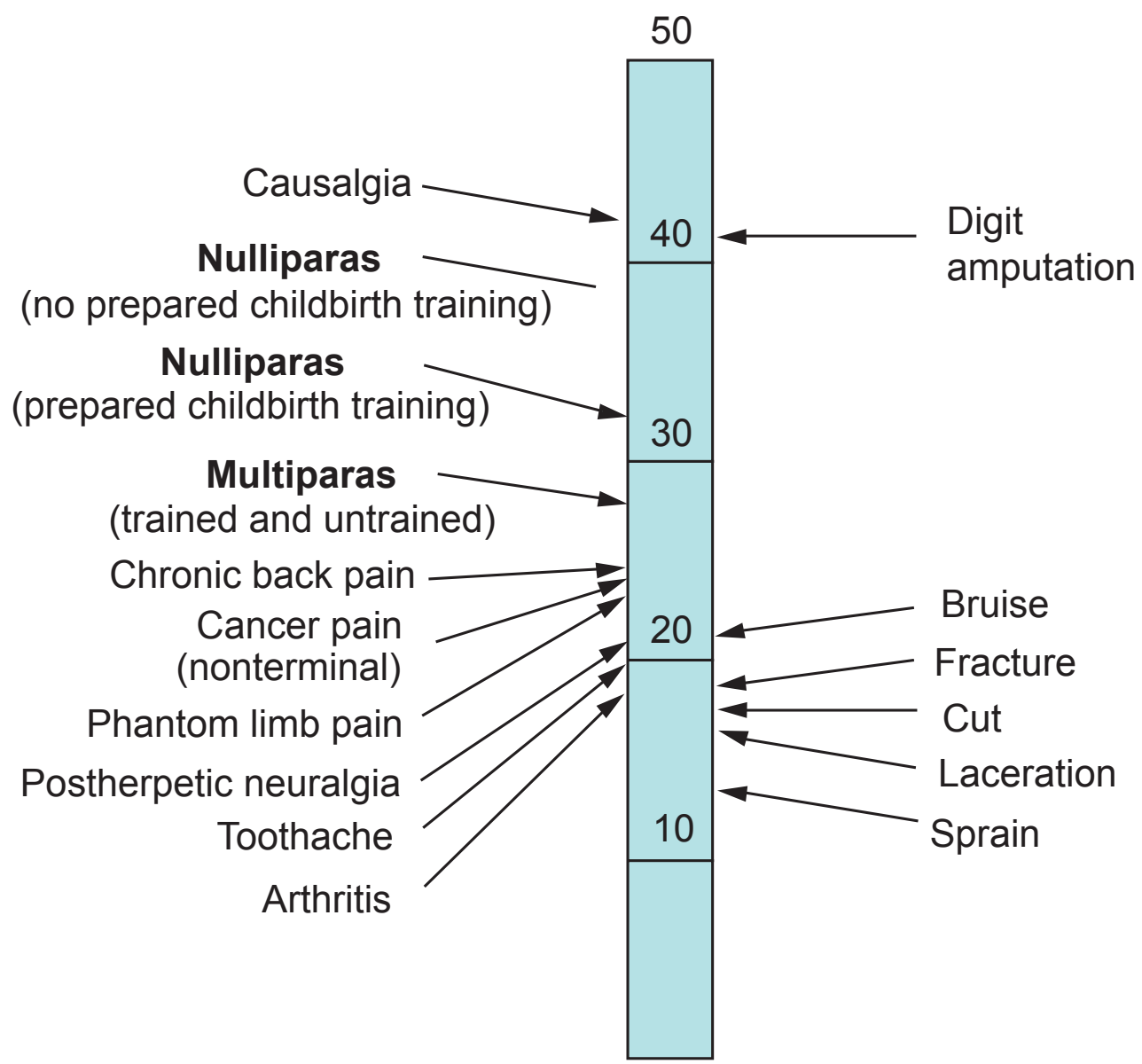

Figure I Comparison of pain scores using the McGill Pain Questionnaire obtained from women during labor and from patients in general hospital clinics and an emergency department. The pain rating index (PRI) represents the sum of the rank values for all words chosen from 20 sets of pain descriptions. From Melzack R. The myth of painless childbirth [The John J. Bonica Lecture]. Pain. 1984;19(4):321-337. ${ }^{4}$ Copyright (C) 1984. This figure has been reproduced with permission of the International Association for the study of Pain ${ }^{\circledR}\left(\right.$ IASP $\left.^{\circledR}\right)$. The figure may not be reproduced for any other purpose without permission. 
tearing of fascia and subcutaneous tissues and pressure on the skeletal muscles of the perineum.

Painful impulses from the lower uterine segment and cervix are transmitted via visceral afferent nerve fibers which accompany sympathetic nerve fibers and enter the spinal cord at the tenth, eleventh, and twelfth thoracic and first lumbar spinal segments (Figure 2). Somatic sensory impulses from the vagina and perineum are transmitted via the pudendal nerves to the second, third and fourth sacral spinal segments.

As is typical of visceral pain, the pain of the first stage of labor is often referred to the dermatomes supplied by the same spinal cord segments that receive input from the uterus and cervix (T10 to L1). Additionally, during the late first stage and second stage of labor, stimulation of pain-sensitive structures within the pelvic cavity, and pressure on one or more roots of the lumbosacral plexus may result in aching, burning, or cramping discomfort in the thigh, legs, and lower back. Stimulation of these structures contributes to pain referred to the lower lumbar and sacral segments.
The pain may be severe if the fetus is in an abnormal position (eg, occiput posterior).

Visceral C-fibers transmitting pain from the uterus and cervix terminate in the spinal cord in the ipsilateral superficial and deep dorsal horn and the ventral horn in a loose network of synapses, as well as crossing the midline to the contralateral dorsal horn with extensive rostrocaudal extension. ${ }^{6}$ In contrast, somatic afferent fibers terminate in the ipsilateral superficial laminae of the dorsal horn with minimal rostrocaudal fiber extension. Thus, first stage labor pain tends to be diffuse in nature compared to second stage labor pain.

Knowledge of the anatomic basis of the transmission of labor pain underlies the current treatment of labor pain using regional anesthesia techniques. The visceral pain of the first stage of labor can be blocked with bilateral paracervical plexus or lumbar sympathetic blockade (Figure 2). Sacral somatic pain caused by descent of the fetus in the birth canal can be blocked with bilateral pudendal nerve blockade. Epidural and intrathecal blockade (neuraxial blockade)

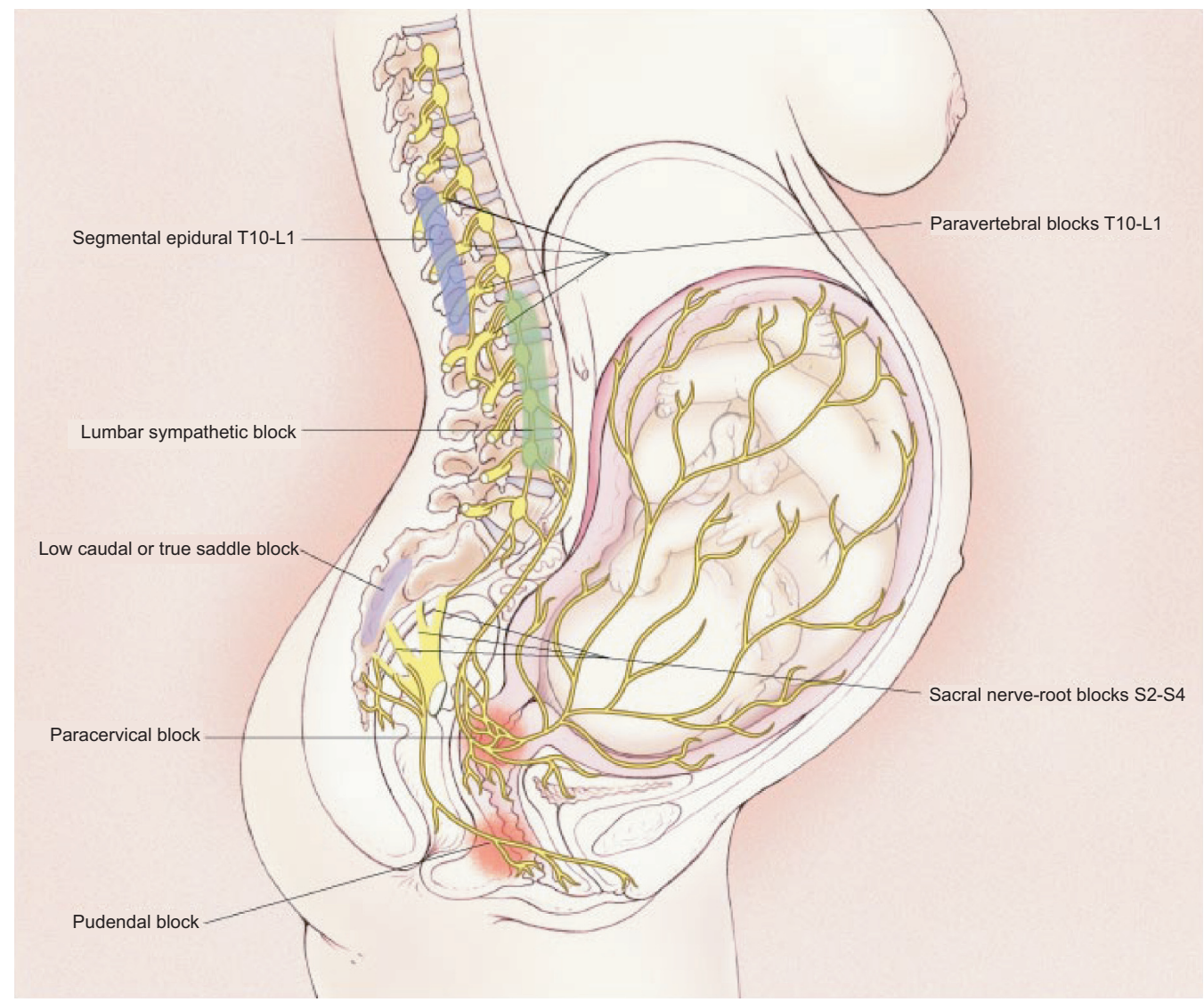

Figure 2 Transmission of labor pain. Labor pain has a visceral component and a somatic component. Noxious impulses from the uterus and cervix follow afferent sensory-nerve fibers that accompany sympathetic nerves, traveling through the paracervical region and the pelvic and hypogastric plexus to enter the lumbar sympathetic chain and the dorsal horn of the spinal cord through the white rami communicantes of the TI0,TII,TI2, and LI spinal nerves. Noxious impulses from the vagina and perineum travel via the pudendal nerve to enter the spinal cord at S2 to S4. Reprinted with permission from Eltzschig HK, Lieberman ES, Camann WR. Regional anesthesia and analgesia for labor and delivery. N Eng J Med. 2003;348(4):319-332. ${ }^{136}$ Copyright (C) 2003 Massachusetts Medical Society. All rights reserved. 
provides complete analgesia for both the first and second stages of labor.

A number of physical and psychologic factors may influence the severity and duration of labor pain and suffering. Physical factors include maternal age, parity, ${ }^{7}$ and maternal condition, the condition of the cervix at the onset of labor, and the relationship of the size and position of the fetus to the size of the birth canal. Many of these factors are interrelated. Generally, older nulliparas experience longer and more painful labors than younger nulliparas. ${ }^{4}$ The parous cervix begins to soften even before the onset of labor and is less sensitive than the nulliparous cervix. The intensity of uterine contractions in early labor tends to be greater in nulliparous than parous women, whereas the reverse is true as labor advances. Dystocia caused by a contracted pelvis, a large baby, or abnormal presentation or position is usually associated with greater pain. Women who go on to have a cesarean delivery after labor have more breakthrough pain during epidural analgesia ${ }^{8}$ and require higher opioid doses during systemic analgesia ${ }^{9}$ than women who deliver vaginally. A history of dysmenorrhea, maternal fatigue, and general debility are associated with higher levels of pain. ${ }^{4}$

Psychological factors, including fear, apprehension, and anxiety, ${ }^{10}$ and the presence of family members ${ }^{11}$ or birthing companions ${ }^{12}$ also influence pain and suffering during childbirth. Education, intense motivation, and cultural factors influence the affective and behavioral dimensions of pain, although they probably minimally affect actual pain sensation. For example, Bonica ${ }^{13}$ observed that women who had predelivery training in psychoprophylaxis manifested little or no pain behavior during childbirth, although when questioned the next day, most of them indicated the process had been quite painful.

\section{Effects of labor pain on the mother and fetus}

Labor pain per se, as well as the tissue damage produced by childbirth, is associated with direct and indirect effects on the mother and fetus. Responses to pain, which include marked stimulation of respiration and circulation, as well as hypothalamic autonomic centers of neuroendocrine function, limbic structures; and psychodynamic behaviors such as anxiety and apprehension, may produce deleterious consequences to the mother and fetus/newborn. Many of these responses are mitigated by effective pain relief.

Labor pain is a powerful respiratory stimulus, resulting in a marked increase in minute ventilation and oxygen consumption during contractions. Compensatory hypoventilation between contractions may cause transient maternal hypoxemia, and potentially, fetal hypoxemia. These periods of hypoventilation may be exacerbated by analgesic techniques that result in respiratory depression (eg, systemic opioid analgesia). Hyperventilation causes severe respiratory alkalosis and a left shift of the maternal oxyhemoglobin dissociation curve, thus diminishing oxygen transfer to the fetus.

The pain and stress of labor activate the sympathetic nervous system, resulting in an increase in plasma catecholamine concentrations, cardiac output and blood pressure. Circulating epinephrine and norepinephrine levels increase by $200 \%$ to $600 \%$ during unmedicated labor ${ }^{14}$ and this increase in catecholamines is associated with a decrease in uterine blood flow. ${ }^{15}$ Severe pain, anxiety and increased catecholamine levels are associated with prolonged or dysfunctional labor. ${ }^{16}$ Epinephrine is a tocolytic and physicians have long observed that an apparent dysfunctional labor pattern can be corrected with effective analgesia. ${ }^{17}$ Finally, unrelieved severe pain may result in serious mental health disturbances that interfere with maternal-neonatal bonding, future sexual relationships, and contribute to postpartum depression, ${ }^{4}$ and rarely, to posttraumatic stress disorder. ${ }^{18}$

Independent of pain, labor and delivery are associated with marked stimulation of the cardiorespiratory system. Uterine contractions displace blood from the uterus to the central circulation (autotransfusion), thus increase cardiac work. Contractions also decrease uteroplacental perfusion, since the uterus is only perfused during uterine diastole. The healthy parturient readily tolerates the large increase in cardiac work, but parturients with heart disease, pulmonary hypertension, or severe pre-eclampsia may not tolerate these changes without adverse outcome. Similarly, while the healthy fetus easily tolerates the changes in uterine blood flow and oxygen delivery, these changes may be deleterious in the setting of uteroplacental insufficiency (eg, pre-eclampsia, intrauterine growth retardation, diabetes mellitus). For these high risk mothers and fetuses, effective analgesia may contribute to better outcomes.

Responses to noxious stimuli during childbirth are the net effects of complex interactions of multiple neurohormonal systems, modulating influences, and psychological factors. These interactions are responsible for the complex physiologic, behavioral, and affective responses that characterize childbirth pain and response to analgesia. Our current understanding of the neurophysiologic basis of childbirth pain is fairly superficial. Better understanding of the pain pathways, neurotransmitters and receptors involved 
in this complex pain will likely present new opportunities for the effective treatment of childbirth pain.

\section{Nonpharmacologic methods of labor analgesia}

Childbirth education, emotional support, massage, aroma therapy, audio-therapy, and therapeutic use of hot and cold have been promulgated as nonpharmacologic methods to relieve or mitigate the pain and suffering of childbirth. Techniques that require specialized training or equipment include hydrotherapy, intradermal water injections, biofeedback, transcutaneous electrical nerve stimulation (TENS), acupuncture or acupressure, and hypnosis. Most of these techniques have not been subject to rigorous scientific study; therefore, conclusions about their efficacy are not possible. ${ }^{19-21}$

Antenatal childbirth education is widely practiced. Studies of the role of childbirth education in influencing outcomes such as use of analgesia, duration of labor, mode of delivery, and incidence of nonreassuring fetal status, are of poor scientific quality and results are inconsistent. For example, observational studies have found that participation in childbirth education classes is associated with a decreased rate of neuraxial analgesia, ${ }^{22,23}$ no change, ${ }^{24}$ or an increased rate. ${ }^{25}$

The parturient's partner or a friend(s) often provide emotional support during childbirth. There is no consistent evidence that this type of support effects childbirth pain. "Continuous labor support" refers to the nonmedical support of the parturient by a trained person, eg, a doula. ${ }^{19}$ Controlled trials and several systematic analyses have concluded that women who received continuous labor support have shorter labors, fewer operative deliveries, fewer analgesic interventions, and greater satisfaction. ${ }^{26-28}$ Neonatal outcome is not altered.

In general, the results from North American trials of continuous labor support do not appear as striking as those from Europe or Africa. ${ }^{19}$ Subgroup analysis of the most recent meta-analysis suggests that benefits are greater when the support person is not a member of the hospital staff. ${ }^{27}$ In any case, all women deserve emotional support during childbirth, whether it is provided by the partner, a family member, a nonprofessional labor companion, or professional hospital staff.

TENS is the application of low-intensity, high-frequency electrical impulses via surface electrodes applied to the lower back. The buzzing, electrical current sensation caused by the TENS unit may reduce the mother's awareness of contraction pain. The parturient controls the degree of stimulation. TENS is widely used in the United Kingdom and Scandinavia for childbirth analgesia. Studies of TENS are inconsistent, but in general, labor pain does not appear to be lessened, nor is the use of other analgesic modalities. ${ }^{19,29}$

Hydrotherapy is the immersion of the parturient in warm water (deep enough to cover the abdomen) during labor (not birth). Systematic reviews of randomized controlled trials have concluded that women who use hydrotherapy experience less pain and use less analgesia, without change in the duration of labor, rate of operative delivery, or neonatal outcome. ${ }^{26,30}$

Intradermal water injection consists of the injection of 0.05 to $0.1 \mathrm{~mL}$ of sterile water, using an insulin or tuberculin syringe, at four sites on the lower back (Figure 3). The injections are acutely painful for 20 to 30 seconds, but as the injection pain fades, so does lower back pain. ${ }^{19}$ Randomized controlled trials have found that the technique is effective in reducing severe back pain during labor, although the rate of use of other analgesic modalities was not different in the treatment compared to control group. ${ }^{19,31}$ There are no known side effects to the mother and fetus.

Prenatal training of the mother, and sometimes her partner, by a trained hypnotherapist is required to learn the technique of self-hypnosis. A meta-analysis of five randomized controlled trials $(n=749)$ concluded that the use of pharmacologic analgesia methods was decreased in the hypnosis compared to controlled group..$^{32}$ Data were inconclusive or limited regarding progress of labor and

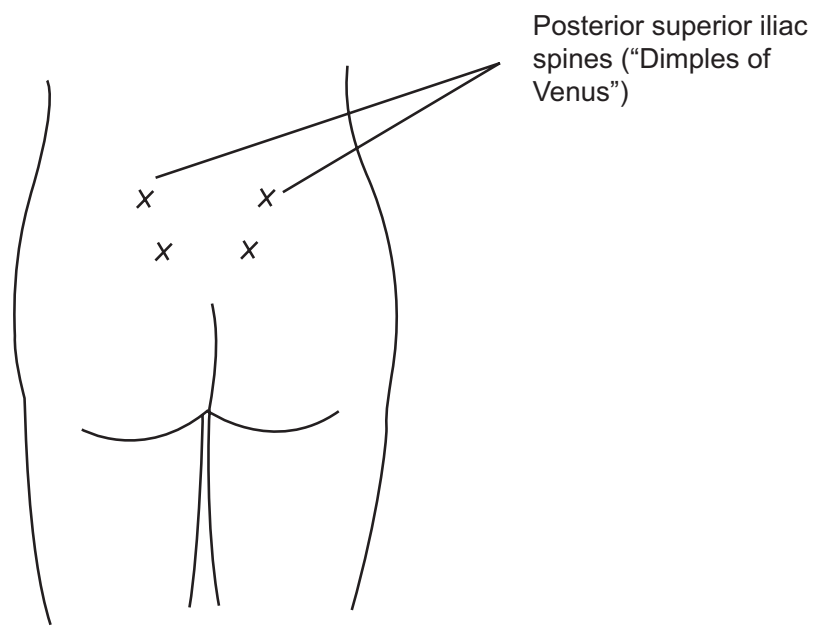

Figure 3 Placement of intradermal water blocks: 4 intradermal injections of 0.05 to $0.1 \mathrm{~mL}$ of sterile water to form 4 small blebs over each posterior superior iliac spine and $3 \mathrm{~cm}$ below and $\mathrm{I} \mathrm{cm}$ medial to each spine. The exact locations of the injections do not appear to be critical to the block success. Reprinted with permission from Simkin P, Bolding A. Update on nonpharmacologic approaches to relieve labor pain and prevent suffering.J Midwifery Womens Health. 2004;49(6):489-504. ${ }^{19}$ Copyright (C) 2004 Elsevier. 
neonatal outcomes. Hypnosis by a trained individual during childbirth is labor-intensive and has not been studied in controlled trials.

Acupuncture is a component of traditional Chinese medicine that has gained popularity in some Western cultures in recent years. In randomized controlled trials conducted in Scandinavian countries ${ }^{33-36}$ and Iran, ${ }^{37}$ women randomized to acupuncture had modestly lower pain scores, and lower use of epidural and systemic opioid analgesia than women randomized to control groups (no or "false" acupuncture). Whether these results can be replicated in other Western societies requires further study.

\section{Systemic analgesia}

Current methods of systemic labor analgesia are inhalation analgesia and systemic opioid analgesia. Inhalation analgesia for labor and vaginal delivery is unusual in the United States, but is more common in other countries. Nitrous oxide is the inhaled anesthetic agent currently in common use. It is available in the United Kingdom as Entonox ${ }^{\circledR}$, a mixture of $50 \%$ nitrous oxide and $50 \%$ oxygen. Special scavenging equipment is necessary to ensure the safe administration of the drug without contamination of environment. The mother should be taught to inhale the mixture correctly, so that peak brain nitrous oxide concentration coincides with peak contraction pain. Use of nitrous oxide for labor analgesia is controversial, as studies are conflicting as to whether the drug actually provides benefit. ${ }^{38-40}$ The intermittent use of nitrous oxide, however, appears safe for the mother and fetus/neonate. The risk of maternal hypoxemia may be increased by concomitant use of nitrous oxide and systemic opioids. ${ }^{41,42}$

In the past, volatile halogenated anesthetic agents have been used for labor analgesia. Similar to inhaled nitrous oxide analgesia, analgesia is incomplete, as doses that provide significant analgesia are also associated with significant maternal sedation. Special equipment, including scavenging equipment, is necessary for the safe administration of volatile anesthetic agents in the labor and delivery room environment. The lower blood-gas solubility coefficient of the newer agents, desflurane and sevoflurane, theoretically confer an advantage over the older agents (eg, methoxyflurane, halothane) because of the more rapid onset and offset of analgesia. In a small study, pain relief scores were significantly higher in women who received sevoflurane $0.8 \%$ compared to nitrous oxide $50 \%$, and women preferred sevoflurane. ${ }^{43}$ However, sevoflurane was associated with higher sedation scores, and whether or not volatile agents interfere with the progress of labor (they inhibit uterine contractility) remains to be determined.
Systemic opioid analgesia is widely used around the world, although its use for labor analgesia lacks rigorous scientific study. There is a high incidence of maternal side effects, and at best, analgesia is incomplete. Existing data suggest that opioids provide little significant analgesia. ${ }^{44-46}$ Although meperidine is the most commonly used systemic opioid, there are few studies comparing opioids and little scientific evidence that one opioid is better than another. All have similar, dose-related, maternal and fetal side effects. Maternal side effects include nausea, vomiting, dysphoria, delayed gastric emptying and respiratory depression. All opioids cross the placenta. In utero opioid exposure results in a slower fetal heart rate and decreased beat-to-beat variability. ${ }^{47}$ The risk of neonatal respiratory depression depends on the dose and timing of maternal opioid administration. The active metabolite of meperidine, normeperidine, has a half-life of 60 hours in neonates. ${ }^{48}$

Theoretically, patient-controlled intravenous opioid analgesia (PCIA) has advantages compared to nurse- or midwife-administered opioid analgesia. These advantages include superior analgesia with smaller drug doses, resulting in a lower incidence of side effects, and patient control of analgesia. Studies of PCIA meperidine, ${ }^{49}$ nalbuphine, ${ }^{50}$ fentanyl, ${ }^{51}$ and more recently, remifentanil, have been reported. ${ }^{52-54}$

Remifentanil has theoretical advantages for PCIA compared to other opioids because of its short latency (time to peak effect after IV administration is 60 to 90 seconds $^{55}$ ). Additionally, because of its rapid metabolism by plasma esterases, it may be safer for the neonate. Remifentanil PCIA, with and without background infusions, has been described. Bolus doses have ranged from $0.2 \mu \mathrm{g} / \mathrm{kg}$ to $1 \mu \mathrm{g} / \mathrm{kg}$ with lock-out intervals from 1 to 5 minutes, ${ }^{52-54,56}$ and infusion rates from $0.025 \mu \mathrm{g} / \mathrm{kg} / \mathrm{min}$ to $0.1 \mu \mathrm{g} / \mathrm{kg} / \mathrm{min} .{ }^{52,56}$ Similar to other systemic opioid techniques, data are inconsistent as to whether remifentanil PCIA can provide satisfactory analgesia without an unacceptably high incidence of side effects. ${ }^{56,57}$

\section{Neuraxial analgesia}

Neuraxial labor analgesia is the most complete and effective method of pain relief during childbirth, and the only method that provides complete analgesia without maternal or fetal sedation. Over the past 40 years in the United States, the use of neuraxial analgesia for childbirth has increased dramatically. ${ }^{58}$ In the most recent US survey performed in 2001, over $60 \%$ of women in large maternity hospitals received neuraxial analgesia during labor. ${ }^{58}$ At the Prentice Women's Hospital in Chicago (author's institution) 90\% of laboring women 
receive neuraxial analgesia during labor. The United Kingdom National Health Service Maternity Statistics of 2005-2006 reported that one third of parturients chose neuraxial analgesia during childbirth. ${ }^{59}$ Advantages and disadvantages of neuraxial labor analgesia are listed in Table 1. The most common techniques are continuous lumbar epidural analgesia, and combined spinal-epidural analgesia. Because the duration of most labors are longer than the duration of action of most neuraxial analgesics, single-shot spinal and epidural techniques lack flexibility. Caudal analgesia is uncommon in modern-day labor analgesia because injection of large doses of local anesthetics is required to obtain surgical anesthesia for cesarean delivery. Continuous spinal analgesia requires dural puncture with a large-bore needle and intrathecal placement of an "epidural" catheter, as microcatheters, at least in the United States, are not commercially available. The large dural puncture results in an unacceptably high incidence of postdural puncture (spinal) headache. However, the benefits of continuous spinal anesthesia may outweigh the risks in a subset of high-risk patients.

Contraindications to neuraxial analgesia and anesthesia include patient refusal, pre-existing coagulopathy, infection at the puncture site, and lack of experienced anesthesia providers. Relative contraindications include hemorrhage or other causes of hypovolemia, untreated systemic infection, preload-dependent disease states, and lumbar spine pathology.

Lumbar epidural analgesia has been the mainstay of neuraxial labor analgesia for many years. Placement of an epidural catheter allows maintenance of analgesia until after delivery. Neuraxial anesthesia for emergency cesarean delivery is associated with decreased maternal morbidity and mortality compared to general anesthesia, ${ }^{60}$ therefore, the ability to quickly convert from epidural analgesia to epidural anesthesia is a major benefit of epidural analgesia.

Randomized studies consistently demonstrate that pain scores are lower and patients are more satisfied with epidural analgesia compared to other forms of nonneuraxial analgesia. ${ }^{61,62}$ Injection of anesthetics in the lumbar epidural space allows spread of the anesthetic solution both cephalad and caudad. Neural blockade to the T10 to L1 spinal segments is necessary to relieve the pain of uterine contraction and cervical dilation, whereas blockade of the sacral dermatomes $\mathrm{S} 2$ to $\mathrm{S} 4$ is necessary to block the pain of vaginal and perineal distention.

Lumbar epidural analgesia is usually initiated in the sitting or lateral position. The epidural space is identified with a 17- or 18-gauge epidural needle and a 19- or 20-gauge flexible catheter is passed through the needle into the epidural space; the epidural needle is removed and the catheter is secured. A test dose of lidocaine or bupivacaine with epinephrine is frequently administered to rule out intrathecal or intravascular catheter placement. Unintentional intravascular injection of local anesthetics can result in systemic toxicity and unintentional intrathecal injection can result in total spinal anesthesia, both with disastrous consequences to the mother and baby. Pregnant women are very difficult to resuscitate in general, particularly after cardiac arrest from local anesthetic cardiac toxicity. ${ }^{63}$

After ascertaining that the epidural catheter is not malpositioned, epidural analgesia is initiated by bolus injection of anesthetic(s) into the epidural space. Analgesia is maintained with intermittent bolus injections or a continuous infusion. The catheter is removed after delivery when there is no further need for analgesia/anesthesia.

Combined spinal-epidural (CSE) analgesia has become increasingly popular in the past decade. Onset of analgesia is significantly faster with CSE compared to epidural analgesia ( 2 to 5 minutes vs 15 to 20 minutes). ${ }^{64}$ In early labor, the intrathecal injection of lipid soluble opioids without local anesthetics results in complete analgesia while avoiding motor blockade and decreasing the incidence of hypotension. This technique is ideal for parturients who wish to ambulate. The effective opioid dose is significantly less than

Table I Advantages and disadvantages of neuraxial labor analgesia

\begin{tabular}{ll}
\hline Advantages & Disadvantages \\
\hline - Complete analgesia & $\bullet$ Requires a skilled anesthesia provider \\
- No maternal sedation & $\bullet$ Occasional failed block \\
- Mother able to enjoy and participate in birth & $\bullet$ Sympathectomy leading to maternal hypotension and decreased \\
- Mitigates deleterious reflex responses to pain & uteroplacental perfusion \\
- Minimal or no neonatal sedation & $\bullet$ Prolonged 2nd stage of labor and possible increased risk of instrumental \\
- Continuous analgesia can be converted to surgical anesthesia & vaginal delivery \\
for urgent or emergency cesarean delivery: avoids need for general & $\bullet$ Contraindicated in parturient with coagulopathy or receiving \\
\hline anesthesia and risk of airway catastrophe & anticoagulants \\
\hline
\end{tabular}


that required for systemic or epidural administration and does not result in sedation. The addition of local anesthetic to a lipid soluble opioid results in sacral analgesia within several minutes; whereas it may take several hours after the lumber epidural injection of dilute local anesthetic solutions to obtain complete sacral analgesia. Therefore, CSE analgesia provides more complete analgesia for women in advanced stages of labor, or women whose labor is progressing rapidly and for whom sacral analgesia is an important component of successful neuraxial analgesia. Finally, use of the CSE technique may decrease the incidence of failed epidural analgesia (eg, a nonfunctioning epidural catheter). ${ }^{65}$

There are several disadvantages of CSE analgesia. Dural puncture is required, albeit with a small-gauge needle. The risk of postdural (spinal) headache does not seem to be increased with CSE compared to epidural analgesia. ${ }^{66}$ The incidence of pruritus is higher with intrathecal versus epidural opioids. ${ }^{67}$ After the initiation of CSE analgesia it will be unclear for 1 to 2 hours whether the epidural catheter is functional (eg, properly sited in the epidural space). Therefore, CSE analgesia may not be the technique of choice if a functioning epidural catheter is critical to the safe care of the patient (eg, in the presence of a nonreassuring fetal heart rate pattern, or an anticipated difficult airway).

The most common CSE technique for labor analgesia is the needle-through-needle technique initiated in a mid- or low-lumbar interspinous space. The epidural space is identified with an epidural needle in the standard fashion; the needle then functions as an introducer for a long, small-gauge (25- to 27-gauge) pencil-point spinal needle. After the tip of the spinal needle punctures the dura (Figure 4), the intrathecal $\operatorname{drug}(\mathrm{s})$ is injected, the spinal needle is withdrawn, and an epidural catheter is threaded through the epidural needle into the epidural space. Analgesia is maintained via the epidural catheter, as with traditional epidural analgesia.

\section{Drugs for neuraxial labor analgesia}

The ideal analgesic drug for neuraxial labor analgesia would provide rapid onset of effective analgesia with minimal motor blockade, minimal risk of maternal toxicity, and negligible effect on uterine activity and uteroplacental perfusion. Placental transfer would be limited, as would direct or indirect effects on the fetus and neonate. Finally, the ideal drug would have a long duration of action. Unfortunately, this perfect drug does not currently exist, but the combination of a long-acting amide local anesthetic with a lipid soluble opioid allows this goal to be approached.

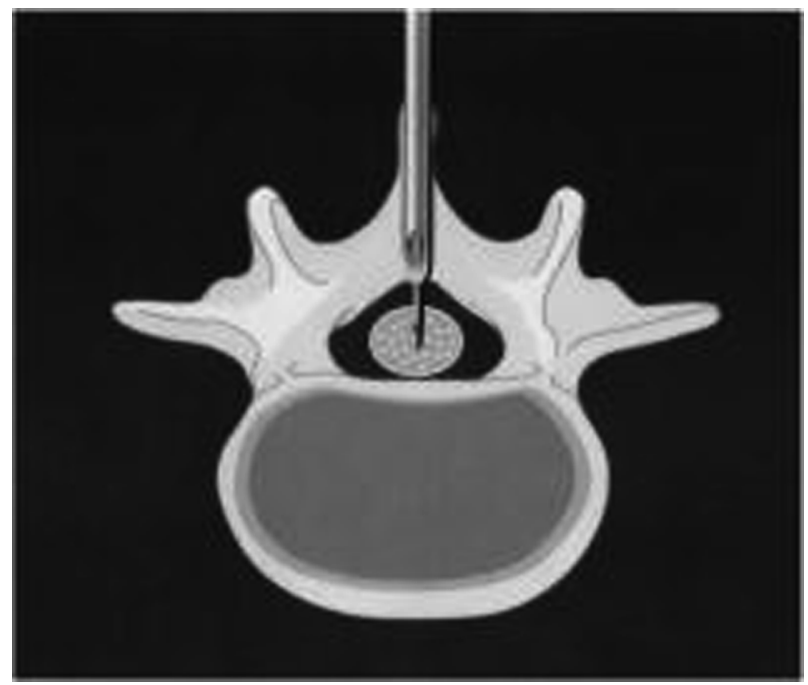

Figure 4 Cross-sectional view of the combined spinal-epidural (CSE) needle-throughneedle technique. The large-gauge epidural needle is sited in the epidural space and the small-gauge spinal needle is passed through the epidural needle and punctures the dura to site in the subarachnoid space. Reprinted with permission from Birnbach DJ, Ojea LS. Combined spinal-epidural (CSE) for labor and delivery. Int Anesthesiol Clin. 2002;40(4):27-48. ${ }^{137}$ Copyright (C) 2002 Lippincott Williams \& Wilkins.

Traditionally, local anesthetics, in particular bupivacaine, were administered to block both the visceral and somatic pain of labor. The discovery three decades ago of opiate receptors in the dorsal horn of the spinal cord ${ }^{68}$ opened up a new era in neuraxial labor analgesia. Neuraxial opioid administration results in opioid binding to these spinal cord receptors with minimal systemic opioid side effects. Intrathecal opioids alone effectively relieve the visceral pain of the early first stage of labor, although they need to be combined with a local anesthetic to effectively block the somatic pain of the late first stage and the second stage of labor.

Neuraxial local anesthetics and opioids appear to act synergistically to provide neuraxial analgesia. ${ }^{69-71}$ The combination of a local anesthetic with a lipid-soluble opioid allows the use of lower doses of each agent, thus minimizing undesirable side effects. The local anesthetic dose required for effective epidural analgesia, when used alone without an opioid, is associated with an unacceptably high incidence of motor blockade. Similarly, high doses of epidural opioid, when used alone, are required for satisfactory analgesia, and these doses are associated with significant systemic absorption and systemic side effects. Latency is an important aspect of labor analgesia; the addition of a lipid soluble opioid to the long-acting/long-latency local anesthetics shortens latency. ${ }^{72}$ Thus, contemporary neuraxial labor analgesia most often incorporates low doses of a long-acting local anesthetic with a lipid-soluble opioid. 
Bupivacaine has been the mainstay of epidural analgesia for many years (Table 2). It is most often used in combination with fentanyl or sufentanil to induce epidural and CSE analgesia. Placental transfer is minimal because the drug is highly protein bound; duration of analgesia is approximately 2 hours. Although lidocaine and 2-chloroprocaine have shorter latencies than bupivacaine, their duration of analgesia is also significantly shorter, thus limiting their usefulness for routine labor analgesia. Additionally, lidocaine is less protein bound than bupivacaine, and therefore has a higher umbilical vein/maternal vein ratio. ${ }^{73}$

Ropivacaine is a homologue of bupivacaine, formulated as a single levorotary enantiomer. Its latency and duration of action are similar to bupivacaine, ${ }^{74}$ but it has less potential for cardiac toxicity. Although potency studies suggest that ropivacaine is approximately $40 \%$ less potent than bupivacaine, ${ }^{75}$ the results of clinical studies comparing low concentrations of ropivacaine and bupivacaine for labor analgesia suggest the two drugs are equipotent in terms of sensory blockade for labor analgesia. ${ }^{76,77}$ Compared to an equipotent sensory dose of bupivacaine, ropivacaine may be associated with less motor blockade; ${ }^{76,78}$ however, this characteristic may not be clinically relevant when low doses of bupivacaine are used.

Levobupivacaine is the S-enantiomer of bupivacaine (which is a racemic mixture), and as such, is also less cardiotoxic than bupivacaine. Onset and duration of action are similar to those of ropivacaine and bupivacaine, but levobupivacaine is associated with less motor blockade than bupivacaine. ${ }^{76,78}$ Levobupivacaine is not available in the United States. Neither ropivacaine nor levobupivacaine are approved for spinal use in the United States although their intrathecal use for labor analgesia has been reported from institutions outside the United States. ${ }^{79}$

Table 2 Drugs for initiation of neuraxial labor analgesia

\begin{tabular}{lll}
\hline $\begin{array}{l}\text { Initiation } \\
\text { of analgesia }\end{array}$ & $\begin{array}{l}\text { Epidural } \\
\text { analgesia }^{\mathrm{a}}\end{array}$ & $\begin{array}{l}\text { Spinal } \\
\text { analgesia }\end{array}$ \\
\hline $\begin{array}{l}\text { Local anesthetics } \\
\mathrm{b}\end{array}$ & $0.0625 \%-0.125 \%$ & $1.25-2.5 \mathrm{mg}$ \\
$\begin{array}{l}\text { Bupivacaine } \\
\text { Ropivacaine }\end{array}$ & $0.08 \%-0.2 \%$ & $2.5-4.5 \mathrm{mg}$ \\
$\quad \begin{array}{l}\text { Levobupivacaine } \\
\text { Opioids }\end{array}$ & $0.0625 \%-0.125 \%$ & $2.5-4.5 \mathrm{mg}$ \\
Fentanyl & $50-100 \mu \mathrm{g}$ & \\
Sufentanil & $5-10 \mu \mathrm{g}$ & $15-25 \mu \mathrm{g}$ \\
\hline
\end{tabular}

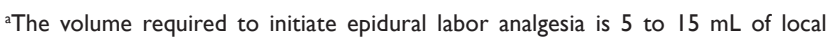
anesthetic solution

'The local anesthetic dose/concentration and the fentanyl or sufentanil dose are reduced if the drugs are combined, or if a local anesthetic-containing epidural test dose is administered before the initiation dose.
Fentanyl or sufentanil is commonly combined with a local anesthetic for spinal and epidural analgesia. Both drugs have a rapid onset (5 to 10 minutes) ${ }^{72,80}$ Their short duration of action (60 to 90 minutes) is overcome by maintaining analgesia with a continuous epidural infusion. Doses commonly used for initiation and maintenance of neuraxial analgesia have been shown to be safe for both the mother and neonate. ${ }^{81,82}$ In contrast, neuraxial morphine has a much slower onset (30 to 60 minutes) and longer duration of action (12 to 24 hours).$^{83}$ In most settings the long duration of action is not beneficial, and the bothersome side effects of morphine (pruritus, nausea and vomiting) continue to be present after delivery. Low-dose morphine ( $\leq 0.25 \mathrm{mg}$ ), however, has been successfully combined with intrathecal bupivacaine and fentanyl for labor analgesia; this combination resulted in short latency and a prolonged duration of analgesia. ${ }^{84-86}$ This combination of drugs may be particularly useful in settings where continuous epidural infusion techniques are impractical and single-shot spinal techniques are used for labor analgesia. ${ }^{84}$

Adjuvants for neuraxial labor analgesia include epinephrine and clonidine. Epinephrine may contribute to analgesia by binding to spinal cord $\alpha_{2}$-adrenergic receptors ${ }^{87}$ and decreasing the uptake of local anesthetics and opioids from the epidural space secondary to vasoconstriction ${ }^{88}$ Clonidine also binds to $\alpha_{2}$-adrenergic receptors and has been shown to supplement epidural labor analgesia. Clonidine is not approved for use in obstetric patients in the United States, however, because of the risks of sedation and hypotension.

\section{Maintenance of neuraxial labor analgesia}

CSE and epidural analgesia may be maintained with intermittent bolus injection, continuous epidural infusion, or patient controlled epidural analgesia, with or without a background infusion. A dilute solution of bupivacaine or ropivacaine combined with fentanyl or sufentanil is commonly used (Table 3). Continuous epidural infusions result in less need for bolus injections ${ }^{89}$ and increased patient satisfaction, ${ }^{90}$ but higher total drug dose ${ }^{89,90}$ compared to intermittent injections. However, the infusion of lower concentration-bupivacaine at a higher rate may result in similar analgesia with less motor block and no increase in total dose..$^{90}$

Patient-controlled epidural analgesia (PCEA) allows for both a continuous epidural infusion and patient-titrated bolus injections. PCEA resulted in greater patient satisfaction ${ }^{91,92}$ and a lower average hourly dose of bupivacaine (and therefore less motor block), ${ }^{92-94}$ The protocols for PCEA vary widely. At one extreme, most of the hourly dose is 
Table 3 Drugs for maintenance of epidural analgesia ${ }^{a}$

\begin{tabular}{ll}
\hline Drug & Concentration \\
\hline Local anesthetics & \\
Bupivacaine & $0.05 \%-0.1 \%$ \\
Ropivacaine & $0.08 \%-0.2 \%$ \\
Opioids & \\
Fentanyl & $1.5-3 \mu \mathrm{g} / \mathrm{mL}$ \\
Sufentanil & $0.2-0.33 \mu \mathrm{g} / \mathrm{mL}$ \\
\hline
\end{tabular}

${ }^{a}$ Continuous infusions usually consist of a local anesthetic combined with an opioid, administered at a rate of 8 to $15 \mathrm{~mL} / \mathrm{h}$ into the lumbar epidural space.

administered via a background infusion which the parturient may supplement with self-administered boluses. At the other extreme, there is no background infusion and the entire dose is self-administered via intermittent boluses. Bupivacaine consumption is higher with background infusions compared to a pure PCEA technique without a background infusion. ${ }^{95}$ In a recent review, Halpern and Carvalho suggested that administration of approximately one third of the hourly dose via a continuous infusion may minimize the incidence of breakthrough pain while optimizing individual patient titration and drug dose. ${ }^{96}$ Common PCEA parameters include a background infusion of 5 to $8 \mathrm{~mL} /$ hour, a bolus dose of 5 to $10 \mathrm{~mL}$, and a lock-out interval of 10 to 20 minutes.

The term "walking" or "mobile" epidural analgesia was first coined to describe CSE opioid analgesia because motor function was maintained and the ability to walk was not impaired. ${ }^{97}$ However, the term can be applied to any neuraxial analgesic technique that allows safe ambulation. Although the concept of the "walking epidural" is popular in the lay press, many women, once comfortable, prefer to rest or sleep rather than ambulate. However, the ability to walk to the toilet, or sit in a chair at the bedside, is desirable to many laboring women. Although ambulation per se has not been shown to positively or negatively affect the progress or outcome of labor, dense motor blockade may adversely affect the spontaneous vaginal delivery rate (vide infra). Thus, the goal of the anesthesia provider should be to minimize motor blockade, whether or not the patient wishes to ambulate.

Several safeguards are necessary for safe ambulation. After initiation of analgesia, parturients are usually monitored in bed for maternal hypotension and fetal heart rate changes for 30 to 45 minutes. Orthostatic blood pressure and heart rate should be measured, and motor function and balance must be assessed. The patient should not ambulate alone as altered dorsal column function (eg, proprioception) may interfere with balance in some patients despite lack of motor blockade. ${ }^{98}$

\section{Side effects of neuraxial labor analgesia}

Hypotension and pruritus are common side effects of neuraxial analgesia; less common side effects include fetal bradycardia and maternal hyperthermia. Hypotension is the result of local anesthetic blockade of the sympathetic nervous system, leading to vasodilation, increased venous capacitance, decreased preload, and decreased cardiac output. Because uterine blood flow is not autoregulated, a decrease in maternal blood pressure results in a decrease in uteroplacental perfusion. Therefore, maternal blood pressure and fetal heart rate should be monitored for 15 to 30 minutes after the induction of neuroblockade. The mother should be positioned to avoid aortocaval compression and hypotension should be treated with small bolus doses of intravenous vasopressor, for example ephedrine (5 to $10 \mathrm{mg}$ ) or phenylephrine (50 to $100 \mu \mathrm{g}$ ).

Pruritus is more common after intrathecal than epidural or systemtic opioid administration. The cause is unknown; it is not histamine-related. The incidence and severity are dose related. ${ }^{99,100}$ The addition of local anesthetic to intrathecal opioid decreases the incidence and severity of pruritus compared to opioid alone. ${ }^{101}$ Symptoms are usually worst during the initial 30 minutes after drug administration and are usually self-limiting. The one-time administration of naloxone (40 to $80 \mu \mathrm{g}$ ) or nalbuphine ( 2.5 to $5 \mathrm{mg}$ ) is effective for the treatment of severe pruritus.

Fetal bradycardia, not associated with maternal hypotension, sometimes occurs within 15 to 45 minutes after initiation of both epidural and CSE analgesia. The initiation of analgesia is associated with an acute decrease in maternal plasma epinephrine levels. ${ }^{102}$ Epinephrine is a tocolytic. Clark and colleagues ${ }^{103}$ hypothesized that the acute decrease in circulating epinephrine concentration may result in temporary imbalance of uterine tocolytic/tocodynamic forces, resulting in uterine hypertonus, decreased uterine perfusion, and ultimately, fetal bradycardia.

Published observations suggest that uterine hypertonus and fetal bradycardia may follow both intrathecal and epidural analgesia during labor, ${ }^{104}$ although some observations suggest that is may occur more commonly after intrathecal opioid injection. In a systematic review of randomized comparisons of intrathecal opioid analgesia versus any nonintrathecal opioid regimen in laboring women, intrathecal opioid analgesia resulted in a significant increase in the risk of fetal bradycardia (odds ratio $1.8 ; 95 \%$ confidence interval, 1.0 to 3.1$).{ }^{105}$ Fortunately, fetal bradycardia associated with 
labor analgesia does not appear to have a detrimental effect on the outcome of labor. There is no evidence that the cesarean delivery rate is higher in women with neuraxial analgesia associated fetal bradycardia. ${ }^{105-107}$ The bradycardia usually resolves with conservative therapy, including discontinuing exogenous oxytocin and the administration of an intravenous fluid bolus. Nitroglycerine has been used successfully to treat uterine hypertonus associated with the initiation of neuraxial analgesia. ${ }^{108}$

Epidural labor analgesia greater than 6 hours is associated with maternal fever. ${ }^{109,110}$ The mechanism is unknown; it may be a result of increased heat production (eg, shivering), decreased heat loss (inhibition of sweating secondary to neuroblockade, or less heat loss via respiratory tract because of lack of hyperventilation), or alterations in temperature regulation induced by epidural analgesia.

Nausea and vomiting are common during labor; however, the incidence does not seem to worsen during neuraxial analgesia if hypotension is avoided. Shivering is frequently observed during labor and may occur more commonly after epidural analgesia. ${ }^{111}$ In an observational study, $18 \%$ of women shivered before delivery and 15\% of these episodes were associated with normothermia and vasodilation, suggesting a nonthermoregulatory cause of the shivering. ${ }^{112}$ There was no difference in the incidence of shivering between women who chose epidural (bupivacaine/fentanyl) compared to systemic meperidine analgesia.

Observational studies suggest that there is a higher risk of intrapartum and postpartum urinary retention in women who receive epidural labor analgesia compared to nonepidural or no analgesia. ${ }^{113,114}$ It is unclear whether this finding reflects a cause-and-effect relationship or patient selection bias; however, differences among groups appear to resolve by postpartum day one. ${ }^{113}$ Parturients should be regularly observed during labor for evidence of bladder distention, especially if the patient complains of suprapubic pain during a contraction or breakthrough pain. Personal observation suggests that many women can void in the presence of lowdose neuroblockade if escorted to the toilet or offered a bed pan. Inability to void and bladder distention should prompt catheterization to empty the bladder.

Complications of neuraxial analgesia include unintentional dural puncture with an epidural needle (incidence approximately $1.5 \%) .{ }^{115}$ Fortunately, serious complications of neuraxial analgesia (respiratory depression/arrest, total spinal anesthesia, systemic local anesthetic toxicity secondary to inadvertent intravascular injection of local anesthetic, and neuraxial infection) are rare. Although 30\% to $50 \%$ of women complain of back pain after delivery, ${ }^{116,117}$ prospective reports ${ }^{118}$ and randomized controlled trials ${ }^{116,119}$ have failed to show a significant relationship between the use of epidural analgesia and long-term backache.

Breakthrough pain may result from inadequate extent of blockade, either caudad (sacral dermatomes) or cephalad (low thoracic dermatomes), inadequate density of blockade, or unilateral/patchy blockade. Women with rapid progress of labor often have inadequate sacral analgesia. Women in late labor require a denser block, as do women with large or malrotated fetuses, or dysfunctional labor. ${ }^{120}$ Analgesia is reestablished by the incremental injection of more concentrated local anesthetic solution or additional opioid, or a combination of the two, and then increasing the maintenance dose as necessary.

\section{Fetal and neonatal effects of neuraxial analgesia}

Neuraxial analgesia may affect the fetus directly or indirectly, or both. The neonatal depressant effects of drugs administered to the mother in the intrapartum period are usually assessed with neurobehavioral testing. Unfortunately, these tests are quite subjective and lack specificity. Additionally, scientifically rigorous studies are lacking and most of the local anesthetic studies were performed in the era when highdose epidural analgesia was common. There is no evidence for a direct effect of low-dose local anesthetic/opioid neuraxial analgesia. Compared to epidural bupivacaine analgesia, systemic meperidine analgesia is associated with a greater loss of FHR variability and fewer FHR accelerations, ${ }^{47}$ and a higher incidence of neonatal respiratory depression. ${ }^{121}$

The indirect fetal effects of epidural and intrathecal opioids may be more significant than the direct effects. Maternal hypotension may cause a decrease in uteroplacental perfusion and fetal oxygenation. Obviously, if the mother has severe respiratory depression and hypoxemia, fetal hypoxemia and hypoxia will follow. ${ }^{122}$ Fetal bradycardia after initiation of neuraxial analgesia was discussed previously.

\section{Other regional analgesic techniques}

Although neuraxial analgesia is the most effective and flexible analgesic technique for labor and delivery, some parturients may not be candidates for neuraxial analgesia, or may not want it. Other nerve blocks provide acceptable, albeit less flexible, analgesia.

Bilateral deposition of local anesthetic around the paracervical (Frankenhäuser's) ganglia blocks transmission of 
visceral afferent impulses from the uterus and cervix. The block provides analgesia for the first stage of labor, before fetal descent, without somatic sensory or motor block. However, analgesia is not continuous and the somatic pain caused by distension of the pelvic floor, vagina or perineum is unrelieved.

Serious maternal complications are uncommon. Fetal bradycardia is the most common fetal complication; the etiology is unknown. Inadvertent direct fetal scalp injection has been reported ${ }^{123}$ and may be more likely to occur when the block is performed with advanced cervical dilation $(>8 \mathrm{~cm})$.

Similar to a paracervical block, paravertebral lumbar sympathetic blockade interferes with transmission of visceral afferent nerve impulses from the uterus and cervix and provides analgesia for the first stage, but not the second stage of labor. The technique is not continuous, it is technically more difficult to learn and perform, and requires bilateral injections. However, it is associated with less fetal bradycardia than a paracervical block, provides first stage analgesia without any motor block, and may be useful for patients with previous back surgery. Labor progress is accelerated compared to epidural analgesia. ${ }^{124}$

Bilateral blockade of the pudendal nerve provides vaginal, vulvar and perineal anesthesia. The resulting anesthesia is adequate for spontaneous vaginal and low- or outlet-forceps delivery, but not mid-forceps delivery or exploration of the upper vagina, cervix or uterine cavities. Bilateral success rate may be a low as $50 \%{ }^{125}$ The pudendal nerve can be blocked via the transperineal or transvaginal route. Most obstetricians in the United States employ the transvaginal route immediately before delivery. Earlier pudendal nerve blocks (just before or after complete cervical dilation) provide better analgesia, do not increase the incidence of instrumental delivery, and allow for a repeat block should the initial block fail. Maternal and fetal complications of pudendal nerve block are unusual. Fetal complications include fetal trauma and/or direct fetal injection of local anesthetic. ${ }^{126}$

Perineal infiltration of local anesthetic is often done immediately before delivery to provide anesthesia for an episiotomy or repair. It provides no motor relaxation. The injection may be complicated by direct injection of local anesthetic into the fetal scalp resulting in neonatal local anesthetic toxicity.

\section{Effects of analgesia on the progress and outcome of labor}

Controversy has surrounded the issue of the effect of neuraxial labor analgesia on the progress of labor and mode of delivery. Although early investigators noted that neuraxial analgesia appeared to be an effective treatment for dysfunctional labor, ${ }^{17,127,128}$ observational studies uniformly found an association between neuraxial analgesia, prolonged labor, and operative delivery. However, randomized controlled trials comparing neuraxial labor analgesia to systemic opioid analgesia have found no difference in the rate of cesarean delivery between groups. ${ }^{129,130}$ Women with more pain during labor (and thus more likely to request analgesia) have a higher risk of cesarean delivery; $8,9,131$ this association may explain the observed association between neuraxial analgesia and operative delivery. Fetal macrosomia, malposition, and dysfunctional labor are associated with more painful labor and a higher rate of cesarean delivery.

Another concern has been whether early labor (latent phase) initiation of neuraxial analgesia adversely affects the outcome of labor. Again, observational studies suggest that initiation of neuraxial analgesia in early labor is associated with an increased rate of cesarean delivery. Randomized controlled trials, however, have uniformly demonstrated that early labor neuraxial compared to systemic opioid analgesia does not adversely affect the progress and outcome of labor, ${ }^{62,132-134}$ and may actually result in faster labor. ${ }^{62,134}$

Randomized controlled trials comparing neuraxial to systemic opioid analgesia have assessed the risk of instrumental vaginal delivery and duration of labor as secondary outcomes. Systematic review of these trials have concluded that the duration of the first and second stages of labor may be prolonged by approximately 30 and 15 minutes, respectively, and the rate of instrumental forceps delivery may be increased. ${ }^{129,130}$ However, the treatment (neuraxial) group in many of the trials received epidural analgesia with bupivacaine $2.5 \mathrm{mg} / \mathrm{mL}$, a much higher dose than is the current norm. Indeed, several groups of investigators have demonstrated that neuraxial analgesia with this technique results in a higher instrumental vaginal delivery rate compared to low-dose bupivacaine-opioid techniques. ${ }^{67,135}$ Thus, the goal of the anesthesia provider should be to provide analgesia with minimal motor blockade in order to decrease the risk of instrumental vaginal delivery.

No randomized trials have compared neuraxial or systemic opioid analgesia to no analgesia. For ethical reasons, these trials are unlikely to ever be completed. Therefore, the effect of any type of analgesia, be it neuraxial or systemic, on the outcome of labor is not known.

\section{Disclosures}

The author declares no conflicts of interest. 


\section{References}

1. von Steinbüchel R. Vorläufige Mitteilung über die Anwendung des Skopolamin-Morphium-Injektionen in der Geburtshilfe. Zentrallblatt Gyn. 1902;30:1304-1306.

2. Caton D. The history of obstetric anesthesia. In: Chestnut DH, Polley LS, Tsen LC, Wong CA, eds. Obstetric Anesthesia Principles and Practice. 4th ed. Philadelphia: Elsevier Mosby; 2009:3-13.

3. Hingson RA, Edwards WB. Continuous caudal analgesia: An analysis of the first ten thousand confinements thus managed with the report of the authors' first thousand cases. JAMA. 1943;123:538-546.

4. Melzack R. The myth of painless childbirth (the John J. Bonica lecture). Pain. 1984;19(4):321-337.

5. Wong CA. Obstetric Pain. In: Ballantyne JC, Rathmell JP, Fishman SM, eds. Bonica's Management of Pain. 4th ed. Philadelphia: Lippincott Williams \& Wilkins; In press.

6. Pan P, Eisenach JC. The pain of childbirth and its effect on the mother and the fetus. In: Chestnut DH, Polley LS, Tsen LC, Wong CA, eds. Obstetric Anesthesia Principles and Practice. 4th ed. Philadelphia: Elsevier Mosby; 2009:387-404.

7. Sheiner E, Sheiner EK, Shoham-Vardi I. The relationship between parity and labor pain. Int J Gynaecol Obstet. 1998;63(3):287-288.

8. Hess PE, Pratt SD, Soni AK, Sarna MC, Oriol NE. An association between severe labor pain and cesarean delivery. Anesth Analg. 2000;90(4):881-886.

9. Alexander JM, Sharma SK, McIntire DD, Wiley J, Leveno KJ. Intensity of labor pain and cesarean delivery. Anesth Analg. 2001;92(6): 1524-1528.

10. Lang AJ, Sorrell JT, Rodgers CS, Lebeck MM. Anxiety sensitivity as a predictor of labor pain. Eur J Pain. 2006;10(3):263-270.

11. Henneborn WJ, Cogan R. The effect of husband participation on reported pain and probability of medication during labor and birth. J Psychosom Res. 1975;19(3):215-222.

12. Kennell J, Klaus M, McGrath S, Robertson S, Hinkley C. Continuous emotional support during labor in a US hospital: a randomized controlled trial. JAMA. 1991;265(17):2197-2201.

13. Bonica JJ. Principles and Practice of Obstetric Analgesia and Anesthesia. Vol 2. Philadelphia: FA Davis; 1969.

14. Lederman RP, McCann DS, Work B Jr, Huber MJ. Endogenous plasma epinephrine and norepinephrine in last-trimester pregnancy and labor. Am J Obstet Gynecol. 1977;129(1):5-8.

15. Shnider SM, Abboud T, Artal R, Henriksen EH, Stefani SJ, Levinson G. Maternal catecholamines decrease during labor after lumbar epidural analgesia. Am J Obstet Gynecol. 1983;147:13-15.

16. Lederman RP, Lederman E, Work B, McCann DS. Anxiety and epinephrine in multiparous labor: Relationship to duration of labor and fetal heart rate pattern. Am J Obstet Gynecol. 1985;153(8):870-877.

17. Moir DD, Willocks J. Management of incoordinate uterine action under continuous epidural analgesia. Br Med J. 1967;3:396-400.

18. Ballard CG, Stanley AK, Brockington IF. Post-traumatic stress disorder (PTSD) after childbirth. Br J Psychiatry. 1995;166(4):525-528.

19. Simkin P, Bolding A. Update on nonpharmacologic approaches to relieve labor pain and prevent suffering. J Midwifery Womens Health. 2004;49(6):489-504.

20. Field T. Pregnancy and labor alternative therapy research. Altern Ther Health Med. 2008;14(5):28-34.

21. Tournaire M, Theau-Yonneau A. Complementary and alternative approaches to pain relief during labor. Evid Based Complement Alternat Med. 2007;4(4):409-417.

22. Hetherington SE. A controlled study of the effect of prepared childbirth classes on obstetric outcomes. Birth. 1990;17(2):86-90.

23. Scott JR, Rose NB. Effect of psychoprophylaxis (Lamaze preparation) on labor and delivery in primiparas. $N$ Engl $\mathrm{J} \mathrm{Med}$. 1976;294(22):1205-1207.

24. Patton LL, English EC, Hambleton JD. Childbirth preparation and outcomes of labor and delivery in primiparous women. J Fam Pract. $1985 ; 20(4): 375-378$.
25. Fabian HM, Radestad IJ, Waldenstrom U. Childbirth and parenthood education classes in Sweden. Women's opinion and possible outcomes. Acta Obstet Gynecol Scand. 2005;84(5):436-443.

26. Simkin PP, O'Hara M. Nonpharmacologic relief of pain during labor: systematic reviews of five methods. Am J Obstet Gynecol. 2002;186(5 Suppl Nature):S131-S159.

27. Hodnett ED, Gates S, Hofmeyr GJ, Sakala C. Continuous support for women during childbirth. Cochrane Database Syst Rev. 2007;(3): CD003766.

28. McGrath SK, Kennell JH. A randomized controlled trial of continuous labor support for middle-class couples: effect on cesarean delivery rates. Birth. 2008;35(2):92-97.

29. Dowswell T, Bedwell C, Lavender T, Neilson JP. Transcutaneous electrical nerve stimulation (TENS) for pain relief in labour. Cochrane Database Syst Rev. 2009;(2):CD007214.

30. Cluett ER, Nikodem VC, McCandlish RE, Burns EE. Immersion in water in pregnancy, labour and birth. Cochrane Database Syst Rev. 2004;(2):CD000111.

31. Huntley AL, Coon JT, Ernst E. Complementary and alternative medicine for labor pain: a systematic review. Am J Obstet Gynecol. 2004;191(1):36-44.

32. Smith CA, Collins CT, Cyna AM, Crowther CA. Complementary and alternative therapies for pain management in labour. Cochrane Database Syst Rev. 2006;(4):CD003521.

33. Skilnand E, Fossen D, Heiberg E. Acupuncture in the management of pain in labor. Acta Obstet Gynecol Scand. 2002;81(10):943-948.

34. Ramnero A, Hanson U, Kihlgren M. Acupuncture treatment during labour - a randomised controlled trial. BJOG. 2002;109(6): 637-644.

35. Borup L, Wurlitzer W, Hedegaard M, Kesmodel US, Hvidman L. Acupuncture as pain relief during delivery: a randomized controlled trial. Birth. 2009;36(1):5-12.

36. Nesheim BI, Kinge R, Berg B, et al. Acupuncture during labor can reduce the use of meperidine: a controlled clinical study. Clin J Pain. 2003;19(3):187-191.

37. Hantoushzadeh S, Alhusseini N, Lebaschi AH. The effects of acupuncture during labour on nulliparous women: a randomised controlled trial. Aust N Z J Obstet Gynaecol. 2007;47(1):26-30.

38. Yentis S. The use of Entonox ${ }^{\circledR}$ for labour pain should be abandoned. Int J Obstet Anesth. 2001;10:25-28.

39. Rosen M. Recent advances in pain relief in childbirth. I. Inhalation and systemic analgesia. Br J Anaesth. 1971;43(9):837-848.

40. Rooks JP. Nitrous oxide for pain in labor - why not in the United States? Birth. 2007;34(1):3-5.

41. Deckardt R, Fembacher PM, Schneider KT, Graeff H. Maternal arterial oxygen saturation during labor and delivery: pain-dependent alterations and effects on the newborn. Obstet Gynecol. 1987;70(1):21-25.

42. Reed PN, Colquhoun AD, Hanning CD. Maternal oxygenation during normal labour. Br J Anaesth. 1989;62(3):316-318.

43. Yeo ST, Holdcroft A, Yentis SM, Stewart A, Bassett P. Analgesia with sevoflurane during labour: ii. Sevoflurane compared with Entonox for labour analgesia. Br J Anaesth. 2007;98(1):110-115.

44. Olofsson C, Ekblom A, Ekman-Ordeberg G, Hjelm A, Irestedt L. Lack of analgesic effect of systemically administered morphine or pethidine on labour pain. Br J Obstet Gynaecol. 1996;103(10):968-972.

45. Bricker L, Lavender T. Parenteral opioids for labor pain relief: a systematic review. Am J Obstet Gynecol. 2002;186(5 Suppl Nature): S94-S109.

46. Nelson KE, Eisenach JC. Intravenous butorphanol, meperidine, and their combination relieve pain and distress in women in labor. Anesthesiology. 2005;102(5):1008-1013.

47. Hill JB, Alexander JM, Sharma SK, McIntire DD, Leveno KJ. A comparison of the effects of epidural and meperidine analgesia during labor on fetal heart rate. Obstet Gynecol. 2003;102(2):333-337.

48. Caldwell J, Wakile LA, Notarianni LJ, et al. Maternal and neonatal disposition of pethidine in childbirth - a study using quantitative gas chromatography-mass spectrometry. Life Sci. 1978;22(7):589-596. 
49. Rayburn W, Leushcen MP, Earl R, Woods M, Lorkovic M, Gaston-Johansson F. Intravenous meperidine during labor: A randomized comparison between nursing and patient-controlled administration. Obstet Gynecol. 1989;74(5):702-704.

50. Podlas J, Breland BD. Patient-controlled analgesia with nalbuphine during labor. Obstet Gynecol. 1987;70(2):202-204.

51. Nikkola EM, Ekblad UU, Kerno PO, Alihanka JM, Salonen MAO. Intravenous fentanyl PCA during labour. Can J Anaesth. 1997;44(12): 1248-1255.

52. Balki M, Kasodekar S, Dhumne S, Bernstein P, Carvalho JC. Remifentanil patient-controlled analgesia for labour: optimizing drug delivery regimens. Can J Anaesth. 2007;54(8):626-633.

53. Blair JM, Dobson GT, Hill DA, McCracken GR, Fee JP. Patient controlled analgesia for labour: a comparison of remifentanil with pethidine. Anaesthesia. 2005;60(1):22-27.

54. Volikas I, Male D. A comparison of pethidine and remifentanil patient-controlled analgesia in labour. Int J Obstet Anesth. 2001; 10(2):86-90.

55. Scott LJ, Perry CM. Remifentanil: a review of its use during the induction and maintenance of general anaesthesia. Drugs. 2005;65(13): 1793-1823.

56. Olufolabi AJ, Booth JV, Wakeling HG, Glass PS, Penning DH, Reynolds JD. A preliminary investigation of remifentanil as a labor analgesic. Anesth Analg. 2000;91(3):606-608.

57. Volmanen P, Akural EI, Raudaskoski T, Alahuhta S. Remifentanil in obstetric analgesia: a dose-finding study. Anesth Analg. 2002;94(4):913-917.

58. Bucklin BA, Hawkins JL, Anderson JR, Ullrich FA. Obstetric anesthesia workforce survey: twenty-year update. Anesthesiology. 2005;103(3):645-653.

59. National Health Service Maternity Statistics 2005-06. 2007: http:// www.ic.nhs.uk/statistics-and-data-collections/hospital-care/maternity/ nhs-maternity-statistics-2005-06. Accessed June 11, 2009.

60. Hawkins JL, Koonin LM, Palmer SK, Gibbs CP. Anesthesia-related deaths during obstetric delivery in the United States, 1979-1990. Anesthesiology. 1997;86(2):277-284.

61. Paech MJ. The King Edward Memorial Hospital 1,000 mother survey of methods of pain relief in labour. Anaesth Intensive Care. 1991;19(3):393-399.

62. Wong CA, Scavone BM, Peaceman AM, et al. The risk of cesarean delivery with neuraxial analgesia given early versus late in labor. $N$ Engl J Med. 2005;352(7):655-665.

63. Albright GA. Cardiac arrest following regional anesthesia with etidocaine or bupivacaine. Anesthesiology. 1979;51(4):285-287.

64. D'Angelo RD, Anderson MT, Phillip J, Eisenach JC. Intrathecal sufentanil compared to epidural bupivacaine for labor analgesia. Anesthesiology. 1994;80(6):1209-1215.

65. Pan PH, Bogard TD, Owen MD. Incidence and characteristics of failures in obstetric neuraxial analgesia and anesthesia: a retrospective analysis of 19,259 deliveries. Int J Obstet Anesth. 2004;13(4):227-233.

66. Norris MC, Fogel ST, Conway-Long C. Combined spinal-epidural versus epidural labor analgesia. Anesthesiology. 2001;95(4): 913-920.

67. Nageotte MP, Larson D, Rumney PJ, Sidhu M, Hollenbach K. Epidural analgesia compared with combined spinal-epidural analgesia during labor in nulliparous women. $N$ Engl J Med. 1997;337(24): 1715-1719.

68. Pert CB, Kuhar MJ, Snyder SH. Opiate receptor: autoradiographic localization in rat brain. Proc Natl Acad Sci U S A. 1976;73(10): 3729-3733.

69. Vercauteren M, Meert TF. Isobolographic analysis of the interaction between epidural sufentanil and bupivacaine in rats. Pharmacol Biochem Behav. 1997;58(1):237-242.

70. Polley LS, Columb MO, Wagner DS, Naughton NN. Dose-dependent reduction of the minimum local analgesic concentration of bupivacaine by sufentanil for epidural analgesia in labor. Anesthesiology. 1998;89(3):626-632.
71. Lyons G, Columb M, Hawthorne L, Dresner M. Extradural pain relief in labour: bupivacaine sparing by extradural fentanyl is dose dependent. Br J Anaesth. 1997;78(5):493-497.

72. Justins DM, Francis D, Houlton PG, Reynolds F. A controlled trial of extradural fentanyl in labour. Br J Anaesth. 1982;54(4):409-414.

73. Kennedy RL, Bell JU, Miller RP, et al. Uptake and distribution of lidocaine in fetal lambs. Anesthesiology. 1990;72(3):483-489.

74. Katz JA, Bridenbaugh PO, Knarr DC, Helton SH, Denson DD. Pharmacodynamics and pharmacokinetics of epidural ropivacaine in humans. Anesth Analg. 1990;70(1):16-21.

75. Polley LS, Columb MO, Naughton NN, Wagner DS, van de Ven CJ. Relative analgesic potencies of ropivacaine and bupivacaine for epidural analgesia in labor: implications for therapeutic indexes. Anesthesiology. 1999;90(4):944-950.

76. Beilin Y, Guinn NR, Bernstein HH, Zahn J, Hossain S, Bodian CA. Local anesthetics and mode of delivery: bupivacaine versus ropivacaine versus levobupivacaine. Anesth Analg. 2007;105(3):756-763.

77. Lee BB, Ngan Kee WD, Ng FF, Lau TK, Wong EL. Epidural infusions of ropivacaine and bupivacaine for labor analgesia: a randomized, double-blind study of obstetric outcome. Anesth Analg. 2004;98(4): $1145-1152$.

78. Lacassie HJ, Habib AS, Lacassie HP, Columb MO. Motor blocking minimum local anesthetic concentrations of bupivacaine, levobupivacaine, and ropivacaine in labor. Reg Anesth Pain Med. 2007;32(4):323-329.

79. Van de Velde M, Dreelinck R, Dubois J, et al. Determination of the full dose-response relation of intrathecal bupivacaine, levobupivacaine, and ropivacaine, combined with sufentanil, for labor analgesia. Anesthesiology. 2007;106(1):149-156.

80. Steinberg RB, Powell G, Hu XH, Dunn SM. Epidural sufentanil for analgesia for labor and delivery. Reg Anesth. 1989;14(5):225-228.

81. Bader AM, Fragneto R, Terui K, Arthur GR, Loferski B, Datta S. Maternal and neonatal fentanyl and bupivacaine concentrations after epidural infusion during labor. Anesth Analg. 1995;81(4):829-832.

82. Porter JS, Bonello E, Reynolds F. The effect of epidural opioids on maternal oxygenation during labour and delivery. Anaesthesia. 1996;51(10):899-903.

83. Sinatra RS, Sevarino FB, Chung JH, et al. Comparison of epidurally administered sufentanil, morphine, and sufentanil-morphine combination for postoperative analgesia. Anesth Analg. 1991;72(4):522-527.

84. Minty RG, Kelly L, Minty A, Hammett DC. Single-dose intrathecal analgesia to control labour pain: is it a useful alternative to epidural analgesia? Can Fam Physician. 2007;53(3):437-442.

85. Vasudevan A, Snowman CE, Sundar S, Sarge TW, Hess PE. Intrathecal morphine reduces breakthrough pain during labour epidural analgesia. Br J Anaesth. 2007;98(2):241-245.

86. Hess PE, Vasudevan A, Snowman C, Pratt SD. Small dose bupivacainefentanyl spinal analgesia combined with morphine for labor. Anesth Analg. 2003;97(1):247-252.

87. Curatolo M, Petersen-Felix S, Arendt-Nielsen L, Zbinden AM. Epidural epinephrine and clonidine: segmental analgesia and effects on different pain modalities. Anesthesiology. 1997;87(4):785-794.

88. Salinas FV. Pharmacology of drugs used for spinal and epidural anesthesia and analgesia. In: Wong CA, ed. Spinal and Epidural Anesthesia. New York: McGraw-Hill; 2007:76-109.

89. Bogod DG, Rosen M, Rees GA. Extradural infusion of $0.125 \%$ bupivacaine at $10 \mathrm{~mL} / \mathrm{hr}$ to women during labor. Br J Anaesth. 1987;59(3):325-330

90. Hicks JA, Jenkins JG, Newton MC, Findley IL. Continuous epidural infusion of $0.075 \%$ bupivacaine for pain relief in labour. Anaesthesia. 1988;43(4):289-292.

91. Gambling DR, McMorland GJ, Yu P, Laszlo C. Comparison of patient-controlled epidural analgesia and conventional intermittent "top-up" injections during labor. Anesth Analg. 1990;70(3): 256-261.

92. Curry PD, Pacsoo C, Heap DG. Patient-controlled epidural analgesia in obstetric anaesthetic practice. Pain. 1994;57(1):125-128. 
93. Gambling DR, Yu P, Cole C, McMorland GH, Palmer L. A comparative study of patient controlled epidural analgesia (PCEA) and continuous infusion epidural analgesia (CIEA) during labour. Can J Anaesth. 1988;35(3):249-254.

94. van der Vyver M, Halpern S, Joseph G. Patient-controlled epidural analgesia versus continuous infusion for labour analgesia: a meta-analysis. Br J Anaesth. 2002;89(3):459-465.

95. Vallejo MC, Ramesh V, Phelps AL, Sah N. Epidural labor analgesia: continuous infusion versus patient-controlled epidural analgesia with background infusion versus without a background infusion. J Pain. 2007;8(12):970-975.

96. Halpern SH, Carvalho B. Patient-controlled epidural analgesia for labor. Anesth Analg. 2009;108(3):921-928.

97. Collis RE, Baxandall ML, Srikantharajah ID, Edge G, Kadim MY, Morgan BM. Combined spinal epidural analgesia with ability to walk throughout labour. Lancet. 1993;341(8847):767-768.

98. Parry MG, Fernando R, Bawa GPS, Poulton BB. Dorsal column function after epidural and spinal blockade: implications for the safety of walking following low-dose regional analgesia for labour Anaesthesia. 1998;53:382-387.

99. Wong CA, Scavone BM, Loffredi M, Wang WY, Peaceman AM, Ganchiff JN. The dose-response of intrathecal sufentanil added to bupivacaine for labor analgesia. Anesthesiology. 2000;92(6): 1553-1558.

100. Herman NL, Choi KC, Affleck PJ, et al. Analgesia, pruritus, and ventilation exhibit a dose-response relationship in parturients receiving intrathecal fentanyl during labor. Anesth Analg. 1999;89(2):378-383.

101. Asokumar B, Newman LM, McCarthy RJ, Ivankovich AD, Tuman KJ. Intrathecal bupivacaine reduces pruritus and prolongs duration of fentanyl analgesia during labor: a prospective, randomized controlled trial. Anesth Analg. 1998;87(6):1309-1315.

102. Shnider SM, Abboud TK, Artal R, Henriksen EH, Stefani SJ, Levinson G. Maternal catecholamines decrease during labor after lumbar epidural anesthesia. Am J Obstet Gynecol. 1983;147(1): $13-15$.

103. Clarke VT, Smiley RM, Finster M. Uterine hyperactivity after intrathecal injection of fentanyl for analgesia during labor: a cause of fetal bradycardia? Anesthesiology. 1994;81(4):1083.

104. Nielsen PE, Erickson JR, Abouleish EI, Perriatt S, Sheppard C. Fetal heart rate changes after intrathecal sufentanil or epidural bupivacaine for labor analgesia: incidence and clinical significance. Anesth Analg. 1996;83(4):742-746.

105. Mardirosoff C, Dumont L, Boulvain M, Tramer MR. Fetal bradycardia due to intrathecal opioids for labour analgesia: a systematic review. Br J Obstet Gynaecol. 2002;109(3):274-281.

106. Albright GA, Forster RM. Does combined spinal-epidural analgesia with subarachnoid sufentanil increase the incidence of emergency cesarean delivery? Reg Anesth. 1997;22(5):400-405

107. Van de Velde M, Teunkens A, Hanssens M, Vandermeersch E, Verhaeghe J. Intrathecal sufentanil and fetal heart rate abnormalities: a double-blind, double placebo-controlled trial comparing two forms of combined spinal epidural analgesia with epidural analgesia in labor. Anesth Analg. 2004;98(4):1153-1159.

108. Mercier FJ, Dounas M, Bouaziz H, Lhuissier C, Benhamou D. Intravenous nitroglycerin to relieve intrapartum fetal distress related to uterine hyperactivity: a prospective observational study. Anesth Analg. 1997;84(5):1117-1120.

109. Camann WR, Hortvet LA, Hughes N, Bader AM, Datta S. Maternal temperature regulation during extradural analgesia for labour. $\mathrm{Br} J$ Anaesth. 1991;67(5):565-568.

110. Lieberman E, Lang JM, Frigoletto F Jr, Richardson DK, Ringer SA, Cohen A. Epidural analgesia, intrapartum fever, and neonatal sepsis evaluation. Pediatrics. 1997;99(3):415-419

111. Kapusta L, Confino E, Ismajovich B, Rosenblum Y, David MP. The effect of epidural analgesia on maternal thermoregulation in labor. Int J Gynaecol Obstet. 1985;23(3):185-189.
112. Panzer O, Ghazanfari N, Sessler DI, et al. Shivering and shivering-like tremor during labor with and without epidural analgesia. Anesthesiology. 1999;90(6):1609-1616.

113. Weiniger CF, Wand S, Nadjari M, et al. Post-void residual volume in labor: a prospective study comparing parturients with and without epidural analgesia. Acta Anaesthesiol Scand. 2006;50(10):1297-1303.

114. Olofsson CI, Ekblom AO, Ekman-Ordeberg GE, Irestedt LE. Postpartum urinary retention: a comparison between two methods of epidural analgesia. Eur J Obstet Gynecol Reprod Biol. 1997;71(1):31-34.

115. Choi PT, Galinski SE, Takeuchi L, Lucas S, Tamayo C, Jadad AR. PDPH is a common complication of neuraxial blockade in parturients: a meta-analysis of obstetrical studies. Can J Anaesth. 2003;50(5): 460-469.

116. Loughnan BA, Carli F, Romney M, Dore CJ, Gordon H. Epidural analgesia and backache: a randomized controlled comparison with intramuscular meperidine for analgesia during labour. $\mathrm{Br} J$ Anaesth. 2002;89(3):466-472.

117. Russell R, Dundas R, Reynolds F. Long term backache after childbirth: prospective search for causative factors. BMJ. 1996;312(7043) 1384-1388.

118. Breen TW, Ransil BJ, Groves PA, Oriol NE. Factors associated with back pain after childbirth. Anesthesiology. 1994;81(1):29-34.

119. Howell CJ, Kidd C, Roberts W, et al. A randomised controlled trial of epidural compared with non-epidural analgesia in labour. BJOG. 2001;108(1):27-33.

120. Hess PE, Pratt SD, Lucas TP, et al. Predictors of breakthrough pain during labor epidural analgesia. Anesth Analg. 2001;93(2):414-418.

121. Ramin SM, Gambling DR, Lucas MJ, Sharma SK, Sidawi JE, Leveno KJ. Randomized trial of epidural versus intravenous analgesia during labor. Obstet Gynecol. 1995;86(5):783-789.

122. Ferouz F, Norris MC, Leighton BL. Risk of respiratory arrest after intrathecal sufentanil. Anesth Analg. 1997;85(5):1088-1090.

123. O'Meara OP, Brazie JV. Neonatal intoxication after paracervical block [letter]. N Engl J Med. 1968;278(20):1127-1128.

124. Leighton BL, Halpern SH, Wilson DB. Lumbar sympathetic blocks speed early and second stage induced labor in nulliparous women. Anesthesiology. 1999;90(4):1039-1046.

125. Scudamore JH, Yates MJ. Pudendal block - a misnomer? Lancet. 1966; 1(7427):23-24.

126. Chase D, Brady JP. Ventricular tachycardia in a neonate with mepivacaine toxicity. J Pediatr. 1977;90(1):127-129.

127. Climie CR. The place of continuous lumbar epidural analgesia in the management of abnormally prolonged labour. Med J Aust. 1964;2:447-450.

128. Reich AM. Paravertebral lumbar sympathetic block in labor: a report on 500 deliveries by a fractional procedure producing continuous conduction anesthesia. Am J Obstet Gynecol. 1951;61(6):1263-1276.

129. Leighton BL, Halpern SH. The effects of epidural analgesia on labor, maternal, and neonatal outcomes: a systematic review. Am J Obstet Gynecol. 2002;186(5 Suppl Nature):S69-S77.

130. Sharma SK, McIntire DD, Wiley J, Leveno KJ. Labor analgesia and cesarean delivery: an individual patient meta-analysis of nulliparous women. Anesthesiology. 2004;100(1):142-148.

131. Panni MK, Segal S. Local anesthetic requirements are greater in dystocia than in normal labor. Anesthesiology. 2003;98(4):957-963.

132. Chestnut DH, Vincent RD, McGrath JM, Choi WW, Bates JN. Does early administration of epidural analgesia affect obstetric outcome in nulliparous women who are receiving intravenous oxytocin? Anesthesiology. 1994;90(6):1193-1200.

133. Chestnut DH, McGrath JM, Vincent RD, et al. Does early administration of epidural analgesia affect obstetric outcome in nulliparous women who are in spontaneous labor? Anesthesiology. 1994;80(6):1201-1208.

134. Ohel G, Gonen R, Vaida S, Barak S, Gaitini L. Early versus late initiation of epidural analgesia in labor: does it increase the risk of cesarean section? A randomized trial. Am J Obstet Gynecol. 2006;194(3):600-605. 
135. Comparative Obstetric Mobile Epidural Trial Study Group UK. Effect of low-dose mobile versus traditional epidural techniques on mode of delivery: a randomised controlled trial. Lancet. 2001; 358(9275):19-23.

136. Eltzschig HK, Lieberman ES, Camann WR. Regional anesthesia and analgesia for labor and delivery. $N$ Eng J Med. 2003; 348(4):319-332.
137. Birnbach DJ, Ojea LS. Combined spinal-epidural (CSE) for labor and delivery. Int Anesthesiol Clin. 2002;40(4):27-48.

International Journal of Women's Health

Dovepress

\section{Publish your work in this journal}

The International Journal of Women's Health is an international, peerreviewed open-access journal publishing original research, reports, reviews and commentaries on all aspects of women's healthcare including gynaecology, obstetrics, and breast cancer. Subject areas include: Chronic conditions (migraine headaches, arthritis, osteoporosis);

Endocrine and autoimmune syndromes; Sexual and reproductive health; Psychological and psychosocial conditions. The manuscript management system is completely online and includes a very quick and fair peer-review system. Visit http://www.dovepress.com/ testimonials.php to read real quotes from published authors.

Submit your manuscript here: http://www.dovepress.com/international-journal-of-womens-health-journal 